\title{
PERAN GURU DALAM PENCEGAHAN PERILAKU KEKERASAN DI SMA NEGERI 2 SEUNAGAN NAGAN RAYA
}

\author{
Ricky Dear Fitria \\ Program Studi Radiodiagnostik dan Radioterapi Yayasan Sihat Beurata Banda Aceh \\ Jalan Pocut Baren Gampong Keuramat Kota Banda Aceh \\ Email :rickynaganraya@gmail.com
}

\begin{abstract}
The role of the teacher relates to how a teacher is able to understand and determine the limits that must be done in organizing material, interacting and doing the learning process. Violent behavior is the use of force or force with the aim of hurting a weaker person or group, so that the victim feels depressed or traumatized and helpless. This study aims to determine the role of teachers in preventing violent behavior in Sma Negeri 2 Seunagan Nagan Raya. This research is descriptive with cross sectional study approach through total sampling technique. Research data collection was carried out on 11 to 8 December 2019 in SMA 2 Seunagan Nagan with a total of 28 respondents, data collection tools used in the form of a questionnaire scale consisting of 20 question items. Data analysis is presented in the form of a frequency distribution table. The results showed that $64.3 \%$ had a teacher's role as a corrector for the prevention of violent behavior in schools, $60.7 \%$ had a teacher's role as an informer for the prevention of violent behavior in schools, $78.6 \%$ had a teacher's role as a class manager for preventing violent behavior in schools . Based on these data, there is a teacher's role in preventing violent behavior in schools, so the researchers suggest maintaining a good role in providing guidance to students at school.
\end{abstract}

Keywords: Teacher Role, Prevention, Violent Behavior (Bullying)

\begin{abstract}
ABSTRAK
Peran guru berkaitan dengan bagaimana seorang guru mampu memahami dan menentukan batasan yang harus dilakukan dalam mengorganisasi materi, berikteraksi dan melakukan proses pembelajaran. Perilaku kekerasan merupakan penggunaan kekerasan atau kekuatan dengan tujuan menyakiti orang atau kelompok yang lebih lemah, sehingga korban merasa tertekan atau trauma dan tidak berdaya.Penelitian ini bertujuan untuk mengetahui peran guru terhadap pencegahan perilaku kekerasan di SMA Negeri 2 seunagan Nagan Raya. Penelitian ini bersifat deskriptif dengan pendekatan cross sectional study melalui teknik pengambilan sampel total sampling. Pengumpulan data penelitian dilakukan pada tanggal $11 \mathrm{~s} / \mathrm{d} 8$ Desember 2019 di SMA Negeri 2 Seunagan Nagan Raya dengan jumlah responden 28 responden, alat pengumpulan data yang digunakan kuesioner dalam bentuk skala gutman yang terdiri dari 20 item pertanyaan. Analisis data disajikan dalam bentuk table distribusi frekuensi. Hasil penelitian menunjukkan $64,3 \%$ adanya peran guru sebagai korektor terhadap pencegahan perilaku kekerasan disekolah, 60,7\% adanya peran guru sebagai informator terhadap pencegahan perilaku kekerasan di sekolah, 78,6\% adanya peran guru sebagai pengelola kelas terhadap pencegahan perilaku kekerasan di sekolah. Berdasarkan data tersebut maka terdapat peran guru terhadap pencegahan perilaku kekerasan di sekolah, maka peneliti menyarankan untuk mempertahankan peran yang baik dalam memberikan arahan bimbingan kepada murid di sekolah.
\end{abstract}

Kata kunci : Peran Guru, Pencegahan, Perilaku kekerasan (Bullying) 


\section{Pendahuluan}

Masa usia sekolah merupakan masa dimana anak mulai mengalihkan perhatian dan hubungan dari keluarga ke teman-temen sebayanya, Pada masa sekolah anak lebih cenderung menghabikan waktu bermain bersama teman-temanya dari pada keluarga. Anak mulai sering membanding-bandingkan dirinya dengan temannya dis ekolah sehingga mudah dihinggapi rasa takut akan kegagalan dan ejekan temen. Pada masa ini pula anak-anak rentan terhadap perilaku kekerasan di sekolahg. Kekerasan yang dilakukan ini bias dikatakan sebagai perilaku kekerasan. (Gunarsa, 2008).

Kekerasan disekolah memiliki dampak terhadap anak-anak yang menjadi korban, kekerasan dapat mempengaruhi kesehatan mental mareka, mengalami gangguan fisik, prestasi, kesulitan dalam bersoalisasi, dan susah beradaptasi. Sekolah juga memiliki salah satu peran untuk bermain bagi anak, karena mareka penting dalam membentuk perkembangan dan perilaku anak seperti di dalam keluarga. (Maliki, 2009).

Olah sangat penting dalam upaya pencegahan kekerasan yang ada di sekolah. Para pihak sekolah yang telah mengetahui dan memahami tentang bullying serta dampak yang dapat terjadi terhadap anak didiknya perlu melakukann sosialisasi tentang bullying yang sedang marak terjadi kepada guru, karyawan sekolah, anak didik, serta orang tua. (SEJIWA, 2008).

Dalam Pasal 54 Undang-Undang No. 23 Tahun 2002 tentang perlindungan Anak mengatakan bahwa anakdi dalam dan di lingkungan sekolah wajib dilindungi dari tindakan kekerasan yang dilakukan oleh guru, pengelola sekolah atau temantemannya di dalam sekolah yang bersangkutan, atau lembaga pendidikan lainnya.

Menurut Djamarah dalam sugihartono dkk (2007), terdapat beberapa peran dan tugas guru dalam proses pembelajaran yaitu : guru sebagai korektor berperan dalam menilai dan mengoreksi hasil kerja siswa, sikap, tingkah laku, dan perbuatan siswa, baik di dalam maupun diluar sekolah, guru sebagai inspirator diharapkan mampu memberikan inspirasi pada siswa dalam belajar, guru sebagai informator harus mampu memberikan informasi mengenai perkembangan ilmu pengetahuan yang diajarkan, guru sebagai motivatordiharapkan mampu memberikan energy pada siswa untuk aktif belajar, guru sebagai pembimbing diharapkan mampu memberikan bimbingan dan bantuan pada siswa yang menghadapi kesulitan belajar, guru sebagai demonstrator diharapkan dapat memperagakan apa yang disampaikan secara didaktis sehingga siswa akan mudah memahami materi pelajaran, guru sebagai pengelola kelas diharapkan mampu mengelola kelas dengan baik selama proses pembelajaran (Irham \& Wiyani, 2013).

Berdasarkan pernyataan diatas, guru memegang peran yang sangat penting untuk memberikan kesadaran tentang bullying dan mengembangkan suatu kebijakan yang tegas dan konsisten terhadap perilaku ini serta meningkatkan ketrampilan dan dukungan baik terhadap pelaku maupun korban sehingga akan tercapai lingkungan yang aman bagi siswa. (Wisdayanti dalam Saputra, 2013).

Menurut Data komisi perlindungan anak Indoenesia (KPAI), sepanjang Januari 2011 sampai Juni 2015 ada 1.880 kasus kekerasan yang terjadi dilingkungan dilingkungan pendidikan. (Susanti, 2016).

Data yang masuk dalam Badan Pemberdayaan Perempuan dan Anak di Aceh, tercatat selama empat tahun terakhir terjadi 1.326 kasus kekerasan terhadap anak terjadi merata di Kabupaten/Kota. (Yusuf, 2015).

\section{KAJIAN PUSTAKA}

1. Guru

Guru adalah sebagai pengelola kegiatan proses belajar mengajar, dalam hal ini guru bertugas untuk mengarahkan kegiatan belajar siswa agar mencapai tujuan pembelajaran. Dalam pengertian guru, Djamarah (2005) menyatakan bahwa guru merupakan unsir manusiawi dalam 
pendidikan. Guru adalah pendidik dan mengajar pada pendiddikan dari anak usia dini jalur sekolah atau pendidikan formal, pendidikan dasar dan pendidikan menengah. (Soango, 2015).

\section{Peran Guru}

Menurut Djamarah dalam Sugihartono dkk (2007), terdapat beberapa peran dan tugas guru dalam proses pembelajaran.

1. Korektor

2. Inspirator

3. Informator

4. Organisator

5. Motivator

6. Pembimbing

7. Demonstrator

8. Pengelola Kelas.

Menurut Sugiyono dan Hariyanto dalam Irham dan Wiyani (2013), atributatribut lain yang disematkan pada seseorang guru terkait dengan fungsi dan peranperannya, antara lain, guru sebagai teladan, sebagai penasehat, sebagai pembaharu, sebagai pemadu, sebagai pelaksana tugas rutin, sebagai insanvisioner, sebagai pencipta, sebagai penutur cerita dan seorang actor, sebagai pembongkar kemah, sebagai peneliti, sebagai pemandu moral, sebagai pembangun/konstruktor, dan masih banyak lagi atribut lainnya.

3. Perilaku Kekerasan (Bullying) di Sekolah

\section{a. Definisi}

Bullying adalah penggunaan kekuasaan atau kekuatan dengan tujuan menyakiti orang atau kelompok yang lebih lemah, sehingga korban merasa tertekan atau trauma dan tidak berdya. Bullying sudah menajdi trend sekarang yang mulai ditiru oleh siswa dari SMP, SMA bahkan hingga terjadi pada siswa TK dan SD. (Darmawan, 2015).

Menurut Pony Retno Astuti dalam Darmawan (2015), Bullying adalah bagaian dari tindakan agresi yang dilakukan berulang kali oleh seseorang atau anak yang lebih kuat terhadap anak yang lebih lemah baik fisik atau psikis.

Bullying memeiliki beberapa karakteristik, diantaranya yaitu, adanya agresi dan keinginan pelaku untuk menyakiti korbannya secara fisik dan verbal, bullying dilakukan secara berulangulang, dan adanya kesenjangan antara pelaku dan korban dimana pelaku adalah seseorang yang kuat secara fisik dan mental sedangkan korban merupakan seseorang yang lemah, baik fisik maupun mental. Dalam tindakan bullying terdiri dari dua pihak yang memiliki peran saling berlawanan yaitu antara pelaku bullying atau orang yang melakukan tindakan bullying dan korban bullying yaitu orang yang dikenali tindakan bullying. (Darmawan, 2015).

b. Bentuk-Bentuk Perilaku Kekerasan di Sekolah.

Menurut Andri Priyatna dalam Darmawan (2015) bentuk bullying yaitu :

1. Fisik : mendorong, memukul, menjewer, mencubit.

2. Verbal : Mengolok-olok nama panggilan, menakut-nakuti, mengancam.

3. Sosial : menyebarkan gossip, mempermalukan didepan umum.

Semua bentuk bullying pasti membawa dampak buruk bagi korbannya.Bullyiong membuat korbannya mengalami perubahan perilaku yang negative. Secara fisik, bullying mengakibatkan luka ditubuh korbannya. Secara psikis, bullying membuat korbannya merasa tidak aman, takut, terintimidasi, rendah diri, sulit kosentrasi dalam belajar, enggan bersekolah, prestasi belajar menurun, bahkan korban bullying bisa tidak percaya pada lingkungannya. Akibat terburuk dari bullying adalah anak mengalami tekanan mental yang berujung pada stress dan percobaan bunuh diri. (Darmawan, 2015).

c. Faktor-faktor yang menyebabkan perilaku bullying.

Menurut (Asyari dan Dahlia, 2013) ada beberapa factor yang dapat menyebabkan terjadinya perilaku bullying. Faktor-faktor tersebut antara lain sebagai berikut :

1. Faktor Keluarga.

Seseorang yang melakukan bullying seringkali berasal dari keluarga bermasalah, 
dimana orang tua kerap menghukum anaknya secara berlebihan atau situasi dirumah yang penuh agresi dan permusuhan. Hal ini terjadi, karena ia pernah menerima perlakuan bullying pada dirinya, yang mungkin dilakukan oleg seseorang di dalam keluarga.

\section{Faktor Kepribadian}

Salah satu factor terbesar penyebab anak melakukan bullying adalah temperemen. Temperemen adalah karakteristik atau kebiasaan yang terbentuk dari respon emosional. Hal ini mengarah pada perkembangan tingkah laku personalitasdan social anak. Seseorang yang aktif dan impulsive lebih mungkin untuk berlaku bullying dibandingkan orang yang pasif atau pemalu.

\section{Faktor Sekolah}

Tingkat pengawasan di sekolah menentukan banyak dan seringnya terjadi peristiwa bullying. Sebagaimana rendahnya tingkat pengawasan di rumah, rendahnya pengawasan di sekolah berkaitan erat dengan berkembangnya perilaku bullying di kalangan siswa. Pentingnya pengawasan dilakukan terutama di tempat bermain dan lapangan, karena biasanya di kedua tempat tersebut perilaku bullying kerap dilakukan. Penanganan yang tepat dari guru atau pengawas terhadap peristiwa bullying adalah hal yang penting karena perilaku bullying yang tidak ditangani dengan baik akan menyebabkan kemungkinan perilaku itu terulang.

Selain ketiga factor tersebut, ada beberapa factor pendorong atau factor penyebab timbulnya kekerasan terhadap siswa/remaja antara lain sebagai berikut :

a. Kekerasan muncul akibat adanya pelanggaran yang disertai dengan hukuman terutama dengan hukuman fisik.

b. Kekerasan bisa terjadi karena guru tidak faham akan makna kekerasan dan akibat negatifnya. Guru mengira bahwa peserta didikan akan jera dengan hukuman fisik yang diberikannya. Padahal sebaliknya, mareka akan benci, dendam dan tidak respek lagi padanya. c. Komunitas sekolah, karena tidak teraturnya organisasi sekolahtermasuk daya juang yang rendah dari para staf, manajemen kelas yang buruk, sehingga muridnya dijatuhi hukuman, tiadanya pujian bagi murid dan lemahnya kepemimpinan dari para guru dan pengurus sekolah, kehadirannya geng, senjata, dan narkoba.

d. Lingkungan atau masyarakat yang lebih luas. Dalam hal ini, ketidaksetaraan ekonomi dan social antara kelompok yang berbeda. Susunan politis seperti sampai pada tingkat mana masyarakat mampu menegakkan hokum yang ada terhadap kekerasan dan perlindungan social oleh Negara. (Asyari dan Dahlia, 2013).

d. Penanganan atau pencegahan kekerasan di Sekolah.

1. Memahami kekerasan disekolah.

2. Melibatkan komunitas berlingkup sekolah.

3. Melibatkan perubahan.

4. Melakukan analisis kebutuhan.

5. Anak-anak membantu anak lain melalui dukungan teman sebaya.

6. Praktik Restoratif (pemulihan).

7. Metode dukungan kelompok.

8. Daftar periksa komunitas berlingkup sekolah/meningkatkan keamanan sekolah. (Helen Cowie and Dawn Jennifer, 2009).

\section{Metode Penelitian}

Penelitian ini bersifat deskriptif, menggunakan metode pendekatan cross sectional study yaitu data yang menyangkut variable penelitian akan dikumpulkan dalam waktu yang bersamaan dengan pengumpulan data dilakukan menggunakan kusioner. Kemudian data yang diperoleh akan dianalisa secara univariat.

Populasi adalah keseluruhan objek peneliti atau objek yang diteliti. (Notoadmodjo, 2005). Populasi dalam penelitian ini adalah semua guru SMA Negeri 2 Seunagan Nagan Raya yang berjumlah 28 orang guru. Teknik 
Pengambilan sampel dalam penelitian ini menggunakan teknik total sampling yaitu pengambilan sampel secara keseluruhan dari total populasi pada saat penelitian dilakukan yang berjumlah 28 orang guru.

Teknik pengolahan data menggunakan langkah-langkah sebagai berikut : editing, Coding, Transfering, dan Tabulating. Analisa data menggunakan teknik statistic dalam bentuk prosentase untuk masingmasing sub variable dengan terlebih dahulu menggunakan jenjang ordinal.

(Notoadmodjo, 2005).

\section{Hasil Dan Pembahasan}

\section{Data Demografi Responden}

Berdasarkan hasil pengumpulan data yang dilakukan di SMA Negeri 2 Seunagan Nagan Raya Tahun 2019 dengan jumlah sampel 28 orang guru, maka diperoleh hasil data demografi seperti pada table berikut ini

Tabel. 1. Distribusi Frekuensi Data Demografi Guru di SMA Negeri 2 seunagan Nagan Raya Tahun 2019.

\begin{tabular}{|c|c|c|c|}
\hline $\begin{array}{l}\mathrm{N} \\
\mathrm{O}\end{array}$ & $\begin{array}{l}\text { Data } \\
\text { Demograf } \\
\text { i }\end{array}$ & $\begin{array}{l}\text { Frekuen } \\
\text { si }\end{array}$ & $\begin{array}{l}\text { Presentas } \\
\text { e }(\%)\end{array}$ \\
\hline \multirow[t]{6}{*}{1.} & Umur & & \\
\hline & $\begin{array}{l}26-35 \\
\text { Tahun }\end{array}$ & 6 & 21,4 \\
\hline & $\begin{array}{l}36-45 \\
\text { Tahun }\end{array}$ & 4 & 14,3 \\
\hline & $\begin{array}{l}46-55 \\
\text { Tahun }\end{array}$ & 10 & 35,7 \\
\hline & $\begin{array}{l}56-65 \\
\text { Tahun }\end{array}$ & 8 & 28,6 \\
\hline & Jumlah & 28 & $100 \%$ \\
\hline \multirow[t]{4}{*}{2.} & $\begin{array}{l}\text { Pendidika } \\
\mathrm{n}\end{array}$ & & \\
\hline & D-III & 4 & 14,3 \\
\hline & S1 & 24 & 85,7 \\
\hline & Jumlah & 28 & $100 \%$ \\
\hline
\end{tabular}

Sumber data : Data Primer

Berdasarkan Tabel 1. Menunjukkan bahwa distribusi umur guru terbanyak yaitu berusia 46-55 tahun sebanyak 10 orang $(35,7 \%)$. Pendidikan terakhir terbanyak adalah Si sebanyak 24 orang $(85,7 \%)$.

\section{Peran Guru sebagai Korektor terhadap pencegahan perilaku kekerasan di Sekolah}

Berdasarkan hasil pengolahan data untuk sub peran guru sebagai korektor terhadap pencegahan perilaku kekerasan di sekolah SMA Negeri 2 Seunagan Nagan Raya Tahun 2019, diperoleh nilai total $\left(\sum x\right)$ 120 dari 28 responden, sehingga nilai ratarata (x) adalah 4,3 dengan skor perolehan tertinggi adalah 5. Selanjutnya masingmasing responden dikategorikan ada apabila nilai $x \geq 4,3$ dan tidak ada apabila $x<4,3$. Hasil kategori dapat dilihat pada table 2 .

Tabel 2. Distribusi Frekuensi Peran Guru sebagai korektor Terhadap pencegahan perilaku kekerasan di SMA Negeri 2 Seunagan Nagan Raya.Tahun 2019.

\begin{tabular}{|l|l|l|l|}
\hline No & Kategori & Frekuensi & $\begin{array}{l}\text { Presentasi } \\
(\%)\end{array}$ \\
\hline $\begin{array}{l}\text { 1. } \\
\text { 2. }\end{array}$ & $\begin{array}{l}\text { Ada } \\
\text { Tidak } \\
\text { ada }\end{array}$ & 18 & 64,3 \\
10 & 35,7 \\
\hline \multicolumn{2}{|l|}{ Jumlah } & 28 & $100 \%$ \\
\hline
\end{tabular}

Sumber data : Data Primer

Berdasarkan table 2 diatas dapat dilihat bahwa sebagaian besar guru sebagai korektor terghadap pencegahan perilaku kekerasan di SMA Negeri 2 Seunagan Nagan Raya Tahun 2019 berada dalam kategori ada sebanyak 18 orang $(64,3 \%)$.

\section{Peran Guru sebagai Informator terhadap pencegahan perilaku kekerasan di Sekolah}

Berdasarkan hasil pengolahan data untuk sub peran guru sebagai informator terhadap pencegahan perilaku kekerasan di SMA Negeri 2 Seunagan Nagan Raya tahun 2019, diperoleh nilai total $\left(\sum \mathrm{x}\right) 121$ dari 28 responden, sehingga nilai rata-ratanya (x) adalah 4,4 dengan skor perolehan tertinggi adalah 5. Selanjutnya masing-masing responden dikategorikan ada apabila nilai $\mathrm{x}$ $\geq 4,4$ dan tidak ada apabila $x<4,4$. Hasil kategori dapat dilihat pada table dibawah ini 
Tabel 3. Distribusi Frekuensi Peran Guru sebagai Informator Terhadap pencegahan perilaku kekerasan di SMA Negeri 2 Seunagan Nagan Raya. Tahun 2019.

\begin{tabular}{|l|l|l|l|}
\hline No & Kategori & Frekuensi & $\begin{array}{l}\text { Presentasi } \\
(\%)\end{array}$ \\
\hline $\begin{array}{l}\text { 1. } \\
\text { 2. }\end{array}$ & $\begin{array}{l}\text { Ada } \\
\text { Tidak } \\
\text { ada }\end{array}$ & 17 & $60,739,3$ \\
\hline \multicolumn{2}{|l}{ Jumlah } & 28 & $100 \%$ \\
\hline
\end{tabular}

Sumber data : Data Primer

Berdasarkan tabel. 3 diatas dapat dilihat bahwa sebagian besar peran guru sebagai informatory terhadap pencegahan perilaku kekerasan di SMA Negeri 2 Seunagan Nagan Raya Tahun 2019 berada dalam kategori ada sebanyak 17 orang $(60,7 \%)$.

\section{Peran Guru sebagai Pembimbing terhadap pencegahan perilaku kekerasan di Sekolah.}

Berdasarkan hasil pengolahan data untuk sub peran guru sebagai pembimbing terhadap pencegahan perilaku kekerasan di Sekolah SMA Negeri 2 Seunagan Nagan Raya Tahun 2019, diperoleh nilai total $\left(\sum x\right)$ 131 dari 28 responden, sehingga nilai rataratanya (x) adalah 4,7 dengan skor perolehan tertinggi adalah 5. Selanjutnya masing-masing responden dikategorikan ada apabila nilai $\mathrm{x} \geq 4,7$ dan tidak ada apabila $\mathrm{x}$ $<4,7$. Hasil kategori dapat dilihat pada table dibawah ini :

Tabel 4. Distribusi Frekuensi Peran Guru sebagai pembimbing Terhadap pencegahan perilaku kekerasan di SMA Negeri 2 Seunagan Nagan Raya. Tahun 2019.

\begin{tabular}{|l|l|l|l|}
\hline No & Kategori & Frekuensi & $\begin{array}{l}\text { Presentasi } \\
(\%)\end{array}$ \\
\hline $\begin{array}{l}\text { 1. } \\
\text { 2. }\end{array}$ & $\begin{array}{l}\text { Ada } \\
\text { Tidak } \\
\text { ada }\end{array}$ & 226 & $78,621,4$ \\
\hline \multicolumn{2}{|l}{ Jumlah } & 28 & $100 \%$ \\
\hline
\end{tabular}

Sumber data : Data Primer

Berdasarkan tabel 4 diatas dapat dilihat bahwa sebagian besar peran guru sebagai pembimbing terhadap penegahan perilaku kekerasan di SMA Negeri 2 Seunagan Nagan Raya Tahun 2019 berada dalam kategori ada sebanyak 22 orang $(78,6 \%)$.

\section{Peran Guru sebagai Pengelola Kelas terhadap pencegahan perilaku kekerasan di Sekolah.}

Berdasarkan hasil pengolahan data untuk sub peran guru sebagai pengelola kelas terhadap pencegahan perilaku kekerasan di SMA Negeri 2 Seunagan Nagan Raya tahun 2019, diperoleh nilai total $\left(\sum x\right) 127$ dari 28 responden, sehingga nilai rata-ratanya $(\mathrm{x})$ adalah 4,6 dengan skore perolehan tertinggi adalah 5 . Selanjutnya masing-masing responden dikategorikan ada apabila nila $\mathrm{x} \geq 4,6$ dan tidak ada apabila $\mathrm{x}<4,6$, Hasil kategori dapat dilihat pada table dibawah ini :

Tabel 5. Distribusi Frekuensi Peran Guru sebagai pengelola kelas Terhadap pencegahan perilaku kekerasan di SMA Negeri 2 Seunagan Nagan Raya. Tahun 2019.

\begin{tabular}{|l|l|l|l|}
\hline No & Kategori & Frekuensi & $\begin{array}{l}\text { Presentasi } \\
(\%)\end{array}$ \\
\hline $\begin{array}{l}\text { 1. } \\
\text { 2. }\end{array}$ & $\begin{array}{l}\text { Ada } \\
\begin{array}{l}\text { Tidak } \\
\text { ada }\end{array}\end{array}$ & 208 & $71,428,6$ \\
\hline \multicolumn{2}{|l}{ Jumlah } & 28 & $100 \%$ \\
\hline
\end{tabular}

Sumber data : Data Primer

Berdasarkan table 5 diatas dapat dilihat bahwa sebagaian besar peran guru sebagai pengelola kelas terhadap pencegahan perilaku kekerasan di SMA Negeri 2 Seunagan Nagan Raya tahun 2019 berada dalam kategori ada sebanyak 20 orang $(71,4 \%)$.

\section{Peran Guru secara Umum terhadap pencegahan perilaku kekerasan di Sekolah.}

Berdasarkan hasil pengolahan data untuk sub peran guru secara umum terhadap pencegahan perilaku kekerasan di SMA Negeri 2 Seunagan Nagan Raya tahun 2019, diperoleh nilai total $\left(\sum \mathrm{x}\right) 497$ dari 28 responden, sehingga nilai rata-ratanya $(\mathrm{x})$ adalah 17,7 dengan skor perolehan tertinggi adalah 20. Selanjutnya masing-masing 
responden dikategorikan ada apabila nilai $\mathrm{x}$ $\geq 17,7$ dan tidak ada apabila $\mathrm{x}<17,7$. Hasil kategori dapat dilihat pada table dibawah ini :

Tabel 6. Distribusi Frekuensi Peran Guru secara umum Terhadap pencegahan perilaku kekerasan di SMA Negeri 2 Seunagan Nagan Raya. Tahun 2019.

\begin{tabular}{|l|l|l|l|}
\hline No & Kategori & Frekuensi & $\begin{array}{l}\text { Presentasi } \\
(\%)\end{array}$ \\
\hline $\begin{array}{l}\text { 1. } \\
\text { 2. }\end{array}$ & $\begin{array}{l}\text { Ada } \\
\text { Tidak } \\
\text { ada }\end{array}$ & 1810 & $64,335,7$ \\
\hline \multicolumn{2}{|l}{ Jumlah } & 28 & $100 \%$ \\
\hline
\end{tabular}

Sumber data : Data Primer

Berdasarkan table 6 diatas dapat dilihat bahwa sebagaian besar peran guru secara umum terhadap pencegahan perilaku kekerasan di Sekolah SMA Negeri 2 Seunagan Nagan Raya tahun 2019 berada dalam kategori ada sebanyak 18 orang $(64,3 \%)$.

\section{Pembahasan}

Dari hasil penelitian dapat dilihat bahwa Peran Guru Secara umum terhadap Pencegahan perilaku kekerasan di SMA Negeri 2 Seunagan Nagan Raya tahun 2019, sebagaian besar berada pada kategori ada yaitu 20 orang $(71,4 \%)$. Menurut Yandri (2004) peran guru BK/konselor yaitu memberikan pelayanan kepada siswa sesuai dengan kebutuhannya secara optimaldan efisien, Kemudian melakukan kalaborasi dengan orang tua, kepala sekolah, wakil kepala sekolah, guru mata pelajaran dan termasuk warga sekolah di sekitarnya untuk menyediakan pengawasan yang baik untuk siswa sehingga sikap dan perilakunya dapat dikontrol.

Berdasarkan hasil penelitian yang dilakukan oleh Sakbani (2015) pada guru SMP Negeri 15 Yogyakarta menunjukkan upaya guru bimbingan dan konseling dalam pencegahan bullying antar siswa SMP Negeri 15 Yogyakarta dianggap cukup berasil, meskipun masih tetap dalam perbaikan.
Menurut hasil penelitian yang penulis dapatkan bahwa guru SMA Negeri 2 Seunagan Nagan Raya, hampir semua guru memiliki peran yang baik dalam mengajarkan siswa/siswi pencegahan terjadinya perilaku kekerasan di sekolah, dan guru juga berperan aktif dalam membina siswa/siswi di sekolah dengan berbasgai macam gaya dan bentuk dengan memberikan bimbingan atau motivasi pada siswa/siswi di sekolah.

\section{Kesimpulan Dan Saran \\ Kesimpulan}

Berdasarkan hasil penelitian yang telah dilakukan di SMA Negeri 2 Seunagan Nagan Raya Tahun 2019 terhadap 28 responden dapat disimpulkan sebagai berikut : Peran Guru sebagai Korektor, Informator, Pembimbing, Pengelola kelas dan peran guru secara umum terhadap Pencegahan Perilaku Kekerasan di SMA Negeri 2 Seunagan Nagan Raya Tahun 2019 berada pada kategori ada.

Saran.

Diharapkan bagi responden untuk dapat mempertahankan peran yang baik dalam memberikan arahan bimbingan kepada murid disekolah.

\section{Daftar Pustaka}

Asyari Hasyim, Dahlia Lia, (2013). Tindakan School Bullying Pada Siswa Kelas IX SMP Fajar Ciputat Tanggerang Selatan. http://www.repository.uinjkt.ac.id.

Budiarto, E. (2002). Biostatistik Untuk Kedokteran dan kesehatan dan Kesehatan Masyarakat Jakarta.

Cowie Helen, Dawn Jennifer. (2009) penanganan Kekerasan di Sekolah. PT Macanan Jaya Cemerlang.

Irham Muhammad, Novan Ardi Wiyani. (2013). Psikologi Pendidikan. Jogjakarta: Ar-Ruzz Media.

Notoatmodjo, S. (2005). Metode Penelitian 
Jurnal Sains Riset (JSR)

$p$-ISSN 2088-0952, $e$-ISSN 2714-531X

Kesehatan, Rineka cipta, Jakarta.

Samisih. (2014). Peran Guru Kelas Dalam Menangani Kesulitan Belajar Siswa Sekolah Dasar Melalui Layanan Bimbingan

Belajar.http://ejournal.utp.ac.id/index. php/JMSG/article/view/250.

Suputro Anung, (2013). Hubungan Paparan kekerasan dengan Perilaku Bullying di Sekolah Dasar.http://eprint.uns.ac.id.

Susanti Afriani, (2016). Kekerasan di Sekolah. News.okezone,com/red.

Undang-Undang Nomor 23 Tahun 2012 Tentang Perlindungan Anak, pasal 54. 